\title{
Preliminary Phytochemical Screening and Bioactive Compounds of Swietenia macrophylla Seed Support T1DM and T2DM
}

\author{
M.C. Kamaraj1,*, Akshaya Ramakrishnan ${ }^{1}$, D. Sudhakaran Iyer² \\ ${ }^{1}$ Centre for Product Development, Heavenly Fuel Pvt Ltd, Besant Nagar, Chennai - 600 090, Tamil Nadu India. \\ ${ }^{2}$ Centre for Research and Development, Bharthiyar University, Coimbatore - 641 046, Tamil Nadu, India.
}

\section{ART I C LE DET A I LS}

Article history:

Received 30 August 2021

Accepted 28 September 2021

Available online 09 October 2021

\section{Keywords:}

Swietenia macrophylla

Phytochemical Screening

Antioxidant Activity

Docking Studies

\begin{abstract}
A B S T R A C T
The purpose of this study was to investigate the antidiabetic effect of phytocompounds from Swietenia macrophylla seed using preliminary phytochemical screening, invitro antioxidant activity and molecular docking studies. The powdered seed extract of Swietenia macrophylla was to investigate the phytochemical screening exhibited the presence of alkaloid, phenols, tannins, flavonoids, terpenoids, steroids, carbohydrates, amino acids and proteins as major active constituents. The antioxidant activity of Swietenia macrophylla seed was evaluated by DPPH free radical scavenging assay. Rutin was used as a reference compound. The Swietenia macrophylla seed exhibited $56.0471 \%$ of free radical scavenging activity as compared with rutin. The molecular docking studies performed by using molecular docking server online respectively in which the antidiabetic target namely glutamine:fructose-6-phosphate amidotransferase (GFAT) (PDB id: 2ZJ3) have a potential interaction with swietenine, swietenolide, $\beta$ sitosterol, and fucosterol. In this study, the protein glutamine:fructose-6-phosphate amidotransferase (GFAT) was used from its structure perspectives. Its primary and secondary structures were evaluated using online tools. Its role in antidiabetic was assessed by molecular docking the compounds present in the seed extract of Swietenia macrophylla assayed by GC-MS analysis. This in-silico study demonstrates the interactions of active components of Swietenia macrophylla against Type I and Type II diabetes.
\end{abstract}

\section{Introduction}

Diabetes mellitus (DM) is a set of diseases that results high levels of blood glucose and depends on insulin production. It involves various disorders of lipids and protein metabolism [1]. Among diabetic peoples could enhance severe complications such as kidney failure, heart disease, and stroke. There are two categories of diabetes mellitus namely Type 1 (T1DM) and Type 2 (T2DM). T1DM is an autoimmune disorder in which the immune system is activated and to stop the pancreatic cells then function to produce insulin [2]. If someone has T1DM, regular diet and exercise can reduce the development of kidney damage. T2DM is a progressive disorder in which body develops resistance to regular insulin functions and losses its capacity to regulate sufficient insulin in the pancreas. There is currently no treatment for T2DM which can manage the condition properly but healthy food, lifestyle adaptations and proper medicine can improve the situation to decrease the risk of development into progressive complications especially cardiovascular disorders [3]. Plants are well known in traditional herbal medicine for their hypoglycemic activities that indicates more than 800 plant species showing hypoglycemic activity. Many traditional plants were successfully used for the treatment of diabetes [4]. Through the active compounds various classes of chemical compounds have been isolated from plants [5]. The World Health Organization has recommended that traditional plant treatments for diabetes warrant further evaluation [6]. An antidiabetic agent could exert a beneficial effect in the diabetic situation by enhancing insulin secretion and or by improving insulin action [7]. Nowadays, the use of complementary and alternative medicine and especially the consumption of botanicals have been increasing rapid worldwide, mostly because of the supposedly less frequent side-effects when compared to modern medicine [8]. One such plant is Swietenia macrophylla is a folkmedicinal tree known as Mahogany. The powdered seed in empty stomach is successfully employed for the treatment of diabetes. The effectiveness of seed extract was scientifically evaluated in type I model [9]. An attempt has been taken to investigate the antidiabetic activity of identified bioactive compounds of Swietenia macrophylla seed on type II model through molecular docking. The aim of this research is to investigate the antidiabetic constituents present in the seed extract of Swietenia macrophylla using preliminary phytochemical screening, in vitro antioxidant activity and molecular docking prediction. In-silico docking procedures have also been carried out to examine the interactions of the plant components with diabetic targets. The widespread uses of Swietenia macrophylla in traditional medicine have resulted in significant qualitative analysis of the plant and its active principles.

\section{Experimental Methods}

\subsection{Plant Material}

Swietenia macrophylla was collected from Papanasam surroundings of Tanjore district, Tamil Nadu, India. The plant was identified by Dr. S. John Britto, Director, Rabinat Herbarium and center for Molecular systematic, St. Joseph's College, Trichy, Tamil Nadu, India. The fruits were peeled to get the seeds. The seeds were dried in an oven at $45^{\circ} \mathrm{C}$ for one week, then ground to a coarse powder in a mortar. The dried powder was kept in airtight bottle and used for further analysis.

\subsection{Chemicals}

Folin - Ciocalteu reagent, sodium carbonate, sodium nitrite, aluminium chloride, sodium hydroxide, DPPH (2,2-Diphenyl-1-picryl-hydrazyl), rutin, gallic acid, ferrous chloride, ferric chloride, hydrochloric acid, sulphuric acid, sodium phosphate, ascorbic acid, were purchased from $\mathrm{Hi}-$ Media (Mumbai). All the chemicals and solvents were used as analytical grade.

\subsection{Preliminary Phytochemical Screening}

The preliminary qualitative phytochemical screening of seed extract of Swietenia macrophylla was done to find out the different phytochemical constituents such as alkaloids, phenolic compounds, flavonoids, saponins, tannins, glycosides, steroids, and terpenoids using standard methods [10, 11]. 


\subsection{Determination of Total Phenolics}

The quantitative estimation of phenolics in the extract of Swietenia macrophila seed extract was determined based on the standardized method [12]. About $0.5 \mathrm{~mL}$ of $1 \mathrm{~N}$ Folin-Ciocalteu reagent and $2.5 \mathrm{~mL}$ of $20 \%$ sodium carbonate solution were added, and then the volume was made up to $10 \mathrm{~mL}$ with water. Followed by 40 min dark incubation and the absorbance were recorded at $725 \mathrm{~nm}$ against blank for the estimation of phenolics. The results were based on the calibration curve: $[y=0.029 x-$ $\left.0.065, \mathrm{R}^{2}=0.955\right]$ where $\mathrm{x}$ was the absorbance and $\mathrm{y}$ was the gallic acid equivalents (mg/g) and were expressed in terms of milligrams gallic acid equivalents (GAE) per gram of extract.

\subsection{Determination of Total Flavonoids}

The total flavonoid in the extracts is estimated by the general procedure [13]. To each $300 \mu \mathrm{L}$ of Swietenia macrophila seed extracts $2 \mathrm{~mL}$ of distilled water was added followed by $150 \mu \mathrm{L}$ of $\mathrm{NaNO}_{2}$. The contents of the tubes were subjected to incubation for $6 \mathrm{~min}$ at room temperature. After incubation $150 \mu \mathrm{L}$ of $\mathrm{AlCl}_{3}(10 \%)$ was added and incubated again for $6 \mathrm{~min}$ at room temperature. Then $2 \mathrm{~mL}$ of $4 \% \mathrm{NaOH}$ was added, vortexed well, and kept at room temperature for another $15 \mathrm{~min}$. The absorbance of pink colour thereby developed was read spectrophotometrically at $510 \mathrm{~nm}$. The results were based on the calibration curve: $\left[y=0.002 x+0.006, R^{2}=\right.$ 0.992] where $\mathrm{x}$ was the absorbance, and $\mathrm{y}$ was the rutin equivalents (mg/g) and the results were expressed in terms of milligrams rutin equivalents per gram of extract.

\subsection{In-Vitro Antioxidant Assays}

The radical scavenging activity of the extract was determined by the standardized method of DPPH radical scavenging activity [14]. A methanol solution of the sample extract at various concentrations was added to 5 $\mathrm{mL}$ of $0.1 \mathrm{~mm}$ methanolic solution of DPPH and allowed to stand for 20 $\min$ at $27{ }^{\circ} \mathrm{C}$. The absorbance of the solution was read at $517 \mathrm{~nm}$ using a spectrophotometer. Methanol was served as blank and a solution without powder extract of Swietenia macrophila seed served as the negative control. The mixture of methanol, DPPH, and standard rutin served as the positive control. The radical scavenging ability of the extract is expressed by $\mathrm{IC}_{50}$ value of the extract.

\subsection{Molecular Docking Analysis}

A computational tool offers the advantage of delivering new drug candidates more quickly and at a lower cost. The present work by computational approach used for the following software manipulation of drugs using molecular docking server online web service for calculation of drug likeness. The identified compounds from Switenia macrophylla was used to interact with antidiabetic proteins retrieved from PDB.

\subsection{Protein Sequence}

The antidiabetic protein was retrieved from online database of SWISSPROT [15]. It was obtained through the entry keyword of GFPT1 protein and searched the entire database. The sequence of glutaminefructose-6-phosphate aminotransferase were shown. The GFPT1 protein was retrieved in FASTA format and it was used for the further computational analysis.

\subsection{Primary Structure Prediction}

For physiochemical characterization, theoretical isoelectric point (PI), molecular weight, total number of positive and negative residues, extinction coefficient [16], half-life [17-20], instability index [21], aliphatic index and grand average of hydropathy (GRAVY) [22] were computed using the Expasy Protparm server.

\subsection{Secondary Structure Prediction}

Secondary structure of the protein was determined by using the FASTA sequences of protease and predicted using SOPMA and SOPM [23].

\subsection{Transmembrane Region Identification}

The transmembrane region of GFPT1 protein was examined by SOSUI server [24]. The evaluated transmembrane region was analysed and visualized by Pepwheel [25] using EMBOSS 2.7 suit.

\subsection{Homology Modeling and Validation}

The protein sequence was subjected for comparative homology modeling via Swiss model [26] and evaluate by Rampage online server [27]. The protein was confirmed by using online server procheck [28] and
WHAT IF [29]. The Swiss model executes the sequence alignments and looks for the assumed template protein in the 3D model.

\subsection{Sequence Subjected for Modeling}

$>$ target

MCGIFAYLNYHVPRTRREILETLIKGLQRLEYRGYDSAGVGFDGGNDKDW EANACKIQLIKKKGKVKALDEEVHKQQDMDLDIEFDVHLGIAHTRWATHGE PSPVNSHPQRSDKNNEFIVIHNGIITNYKDLKKFLESKGYDFESETDTETIAKL VKYMYDNRESQDTSFTTLVERVIQQLEGAFALVFKSVHFPGQAVGTRRGSPLL IGVRSEHKLSTDHIPILYRTGKDKKGSCNLSRVDSTTCLFPVEEKAVEYYFASD ASAVIEHTNRVIFLEDDDVAAVVDGRLSIHRIKRTAGDHPGRAVQTLQMELQ QIMKGNFSSFMQKEIFEQPESVVNTMRGRVNFDDYTVNLGGLKDHIKEIQRC RRLILIACGTSYHAGVATRQVLEELTELPVMVELASDFLDRNTPVFRDDVCFF LSQSGETADTLMGLRYCKERGALTVGITNTVGSSISRETDCGVHINAGPEIGVA STKAYTSQFVSLVMFALMMCDDRISMQERRKEIMLGLKRLPDLIKEVLSMDD EIQKLATELYHQKSVLIMGRGYHYATCLEGALKIKEITYMHSEGILAGELKHGP LALVDKLMPVIMIIMRDHTYAKCQNALQQVVARQGRPVVICDKEDTETIKNT KRTIKVPHSVDCLQGILSVIPLQLLAFHLAVLRGYDVDFPRNLAKSVTVE

\subsection{Protein Preparation for Docking}

Docking calculations were carried out on protein models involved in T2DM. The crystalline structures were downloaded from Protein Data Bank website (http://www.rcsb.org/pdb/home/home.do) and saved in $\mathrm{pdb}$ format. In the protein id the Essential hydrogen atoms, Kollman united atom type charges, and salvation parameters were added with the aid of AutoDock tool. Affinity (grid) maps of 20x20x20 Å spacing were generated using Autogrid program. Autodock parameter set and distance-dependent dielectric functions were used in the calculation of the van der Waals and the electrostatic terms respectively [30].

\subsection{GC-MS Compounds}

Through the GC-MS analysis of Swietenia macrophylla performed by Soheil et al. [31], identified swietenine, swietenolide, $\beta$ - sitosterol, and fucosterol compounds and included in this study.

The screened compounds were retrieved from the PubChem compound (http://www.ncbi.nlm.nih.gov/compound) and used for further studies.

\subsection{Ligand Energy Minimization}

The MMFF94 force field [32] was used for energy minimization of ligands molecules using Docking Server. Gasteiger partial charges were added to the ligand atoms. Non-polar hydrogen atoms were merged and rotatable bonds were defined. The ligands were downloaded from the Pubchem software (http://pubchem.ncbi.nlm.nih.gov).

\subsection{Ligand Protein Docking}

Molecular docking studies were carried out using the parameters of molecular docking software (http://www.dockingserver.com). Docking simulations were performed using the Lamarckian genetic algorithm (LGA) and the Solis and Wets local search method [33]. Initial position, orientation and torsions of the ligand molecules were set randomly. Each docking experiment was derived from 100 different runs that were set to terminate after a maximum of 2,500,000 energy evaluations. The population size was set to 150 . During the search, a translational step of $0.2 \AA$, quaternion and torsion steps of 5 were applied.

\section{Results and Discussion}

\subsection{Preliminary Phytochemical Results}

The presence of alkaloids, phenolic compounds, flavonoids, tannins, saponins, steroids, and terpenoids in the seed extract of Swietenia macrophylla was confirmed as shown in Table 1 . The performance of the powdered seed extract of Swietenia macrophylla once reacted to chemical reagents demonstrates the characters individuality for observing the phytoconstituents.

\subsection{Determination of Total Phenolics and Flavonoid Contents}

The quantitative phytochemical screening of total phenolics and flavonoids content was analyzed in the seed extract of Switenia macrophylla (Table 2). Total phenolic content of Swietenia macrophylla seed extract showed the content value of $78.409 \%$. The total flavonoid content of Swietenia macrophylla seed extract showed the content value of $96.167 \%$. The total flavonoid content was found higher than phenolics in

\subsection{Ligand Retrieved}


Swietenia macrophylla. In phytocmpounds, flavonoids are the phenolic compounds that belong to the chief group of plant phenolics; they are free radical scavengers and are the primary antioxidants. So it plays a significant role in antioxidant activity as well as an important biological function of the plant [34]. Since these compounds were found to be present in the powder extract of Swietenia macrophylla might be responsible for potent antioxidant capacity in scavenging the free radicals.

Table 1 Phytochemical screening of Swietenia macrophylla

\begin{tabular}{lll}
\hline S.No & Phytochemical constituents & Presence or absence \\
\hline 1 & Alkaloids & ++ \\
2 & Phenolic compounds & ++ \\
3 & Tannins & + \\
4 & Flavonoids & + \\
5 & Terpenoids & + \\
6 & Steroids & - \\
7 & Glycosides & - \\
8 & Flavanol glycosides & - \\
9 & Cardiac glycosides & + \\
10 & Saponins & + \\
11 & Phytosterol & + \\
12 & Fixed oils and fats & ++ \\
13 & Carbohydrates & + \\
14 & Proteins & + \\
15 & Amino acids & .
\end{tabular}

$(+)<(++)<(+++)$ : based on the intensity of characteristic

Table 2 Quantitative phytochemical analysis of Swietenia macrophylla

\begin{tabular}{ll}
\hline Quantitative phytochemical analysis & \\
\hline Phytoconstituents & Percentage (\%) \\
Phenolics & 78.409 \\
Flavonoids & 96.167 \\
\hline
\end{tabular}

\subsection{In Vitro Antioxidant Assay}

Antioxidants are the organic constituents who are highly used over natural sources, which are also a mixture of phytocompounds. Outstanding of the intense generation of oxidative stress by prooxidants, a complaint is established wherever the cellular molecules such as proteins, nucleic acids, and lipids suffer oxidative damages and may cause tissue interruption [35]. In such conditions, antioxidants performa vital role in the elimination of oxidative stress. Therefore, the antioxidants found in the powder extract of Switenia macrophylla can play a chief role in stabilizing the free radicals. This study was aimed to evaluate the antioxidant capacity of the seed extract of Swietenia macrophylla to identify its ability to scavenge the free radicals and the results are reported in Table 3. The DPPH scavenging assay was studied by calculating the $\mathrm{IC}_{50}$ values of the extract. Based on the results it was found that the minimum $\mathrm{IC}_{50}$ values were $(50 \mu \mathrm{g} / \mathrm{mL})$ that proved to show the higher ability to scavenge the DPPH radical. Likewise, in control rutin also the efficient free radical scavenging activity was considerably high in the powder extracts of Switenia macrophylla (56.0471\%). DPPH radical scavenging activity is the convenient, easiest, and rapid method for screening antioxidants in plant extracts [36]. Thus the reports showed stronger antioxidant activities as the powder extract of Switenia macrophylla possess the capable amount of natural antioxidants [37].

Table 3 Antioxidant activity of Swietenia macrophylla (DPPH assay (1, 1-diphenyl2-picrylhydrazyl))

\begin{tabular}{llllll}
\hline Sample & Conc. $(\mathrm{mcg} / \mathrm{mL})$ & Absorbance & Control & Inhibition $\%$ & $\mathrm{IC}_{50} \% \mathrm{~mL}$ \\
\hline \multirow{4}{*}{ Swietenia } & 10 & 0.562 & 0.622 & 9.646302 & \\
macrophylla & 20 & 0.452 & 0.622 & 27.33119 & \\
& 40 & 0.333 & 0.622 & 46.46302 & 56.0471 \\
& 50 & 0.226 & 0.622 & 63.66559 & \\
\hline
\end{tabular}

\subsection{Primary Structure Analysis}

The human GFPT1 protein was retrieved from SWISSPROT in FASTA forma. The primary physiochemical parameter was performed and amino acid composition was identified (Tables 4 and 5). The result shows that the GFPT1 protein was composed of 22 amino acids with different ratios. Among that leucin content was more $(9.4 \%)$ that indicate the hydrophobic nature of protein because it has an aliphatic isobutyl side chain and also essential amino acid. This indicates the sequence length is 681, and the molecular weight of protein was found to be 76759.15 , the protein has 6.38 isoelectric points that represent the protein is acidic in nature and it will help to purify the protein molecule. The number of negative charged residues (Asp + Glu) is 92 and number of positive charged residues (Arg + Lys) is 85 . The extinction coefficient was 43165 at $280 \mathrm{~nm}$; it may be probable to avoid interference of other substances. The evaluated value used to determine the quantification of protein-protein or protein-ligand interactions. The quantitative measurement of dynamic equilibrium based on the half-life time. The GFPT1 protein has 30 hours in mammalian reticulocytes; in yeast have 20 hours and 10 hours in E.coli. The stability of protein was determined by using the instability index (41.34). The aliphatic index characterize that the volume of protein occupied by aliphatic chains (Alanine, valine, isoleucine and leucine), GFPT1 protein have 91.86 that denoted unstable in high thermal conditions. Grand Average Hydropathicity denoted that the hydrophobicity of aminoacid residues. Here GFPT 1 protein has -0.250 had a reasonable interaction with water molecule. The protein molecule has 4 different atoms such as $\mathrm{C}, \mathrm{H}, \mathrm{N}, \mathrm{O}$, and $\mathrm{S}$, molecular formula was $\mathrm{C}_{3389} \mathrm{H}_{5429} \mathrm{~N}_{945} \mathrm{O}_{1016} \mathrm{~S}_{34}$.

Table 4 Amino acid composition (\%) of stable factor computed in protparam

\begin{tabular}{lll}
\hline Amino acids & Numbers & Percentage \\
\hline Ala (A) & 40 & $5.9 \%$ \\
Arg (R) & 41 & $6.0 \%$ \\
Asn (N) & 21 & $3.1 \%$ \\
Asp (D) & 45 & $6.6 \%$ \\
Cys (C) & 14 & $2.1 \%$ \\
Gln (Q) & 28 & $4.1 \%$ \\
Glu (E) & 47 & $6.9 \%$ \\
Gly (G) & 46 & $6.8 \%$ \\
His (H) & 23 & $3.4 \%$ \\
Ile (I) & 46 & $6.8 \%$ \\
Lea (L) & 64 & $9.4 \%$ \\
Lys (K) & 44 & $6.5 \%$ \\
Met (M) & 20 & $2.9 \%$ \\
Phe (F) & $3.7 \%$ \\
Pro (P) & 25 & $2.9 \%$ \\
Ser (S) & 20 & $5.6 \%$ \\
Thr (T) & 38 & $6.2 \%$ \\
Trp (W) & 42 & $0.3 \%$ \\
Tyr (Y) & 2 & $3.1 \%$ \\
Val (V) & 21 & $7.9 \%$ \\
Pyl (O) & 54 & $0.0 \%$ \\
Sec (U) & 0 & $0.0 \%$ \\
\hline
\end{tabular}

Table 5 Parameters computed using Expasy's protparam tool

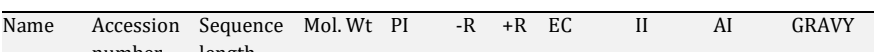
number length
Q

\begin{tabular}{llllllllllll}
\hline GFPT1 & Q06210 & 699 & 76759 & 6.38 & 92 & 85 & 42290 & 41.34 & 91.86 & -0.25
\end{tabular}

Mol.wt- Molecular Weight; PI- Isoelectric point; $-R-$ number of negatively charged residues; $+R-$ number of positively charged residues; $E C-$ Extinction coefficient at 280nm; II - Instability Index; AI - Aliphatic Index; GRAVY - Grand average of Hydropathicity

\subsection{Secondary Structure of Protein}

The secondary structure of GFPT1 protein was predicted by using SOPMA and SOPM (Table 6). The protein was $\alpha$ helix with other structures such as extended stand, $\beta$ turn and random coil. Presents the comparative analysis of SOPMA and SOPM. From which it is clear that random coil is mostly present, when the structure was predicted both by SOPMA and SOPM, followed by extended strand and alpha helix. So this protein is stable in nature.

Table 6 Secondary structure of GFPT1 protein bt SOPMA and SOPM

\begin{tabular}{lll}
\hline Secondary structure & SOPMA & SOPM \\
\hline Alpha helix (Hh) & 309 is $45.37 \%$ & 295 is $43.32 \%$ \\
$3_{10}$ helix (Gg) & 0 is $0.00 \%$ & 0 is $0.00 \%$ \\
Pi helix (Ii) & 0 is $0.00 \%$ & 0 is $0.00 \%$ \\
Beta bridge (Bb) & 0 is $0.00 \%$ & 0 is $0.00 \%$ \\
Extended strand (Ee) & 111 is $16.30 \%$ & 127 is $18.65 \%$ \\
Beta turn (Tt) & 37 is $5.43 \%$ & 58 is $8.52 \%$ \\
Bend region (Ss) & 0 is $0.00 \%$ & 0 is $0.00 \%$ \\
Random coil (Cc) & 224 is $32.89 \%$ & 201 is $29.52 \%$ \\
Ambiguous states (?) & 0 is $0.00 \%$ & 0 is $0.00 \%$ \\
Other ststes & 0 is $0.00 \%$ & 0 is $0.00 \%$ \\
\hline
\end{tabular}

\subsection{Protein Structure Validation}

The physiochemical parameters represent the protein primary properties and then the secondary structure was predicted as alpha helical in nature of transmembrane protein in (Fig. 1) and then the structure was evaluated by PROTTER and Ramachandran plot represents the protein 
validation (Figs. 2 and 3). The predicted GFPT1 protein structure was validated by using Ramachandran plot using PROCHECK software that shows the protein molecule contains 365 residues in that 303 aminoacid most, 24 aminoacid additionally allowed, 01 generally and 0 disallowed region.

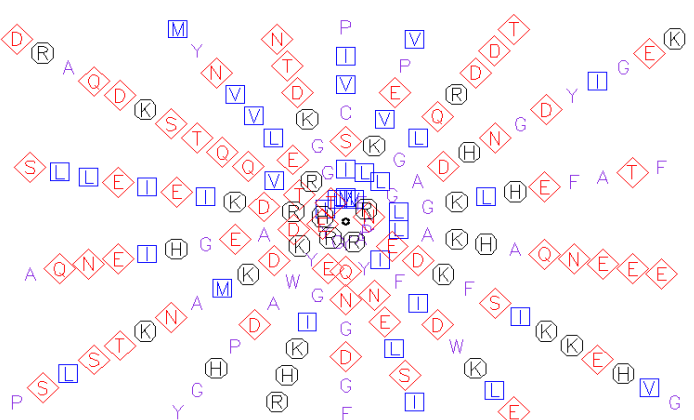

Fig. 1 Pepwheel of 2ZJ3
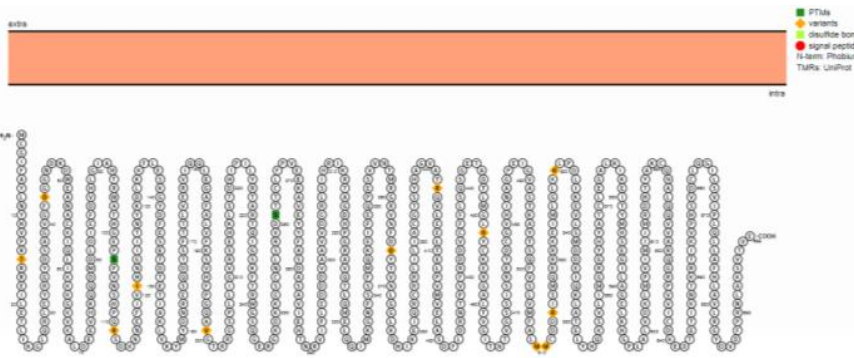

Fig. 2 PROTTER results of Transmembrane region

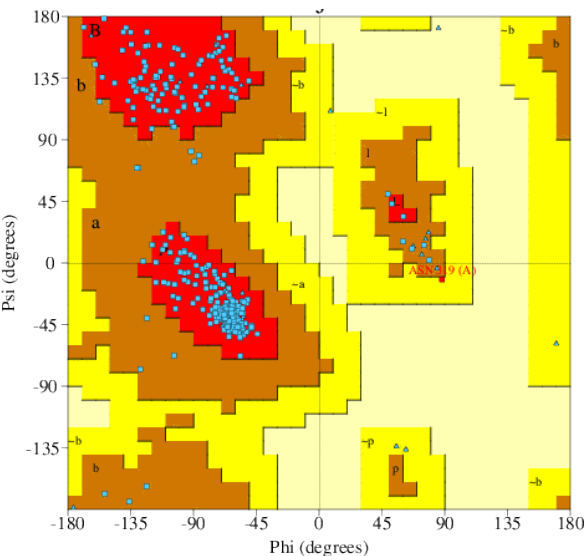

Fig. 3 Ramachandran plot

\subsection{Molecular Docking}

The GFPT1 protein (Fig. 4), and ligands (isolated compounds of Swietenia macrophylla) in Table 7 were subjected to docking studies by using online Auto dock server. The software used to runs 10 docking and were shown in Table 8. The 3D structure of glutamine-fructose-6phosphate aminotransferase (PDB id: 2ZJ3) were optimized to achieve minimal potential energy using molecular docking server. The minimization values are summarized. Docking simulation of 10 runs of plant compound $\beta$-sitosterol, swietenine, swietenolide and fucosterol was performed for a set of catalytic active site of glutamine--fructose-6phosphate aminotransferase (Fig. 5).

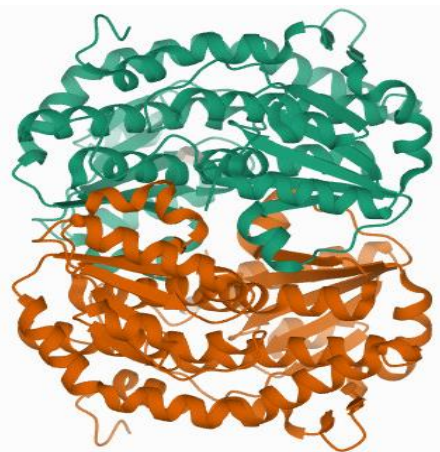

Fig. 4 GFPT1 protein (PDB id: 2ZJ3)

https://doi.org/10.30799/jnpr.099.21070102
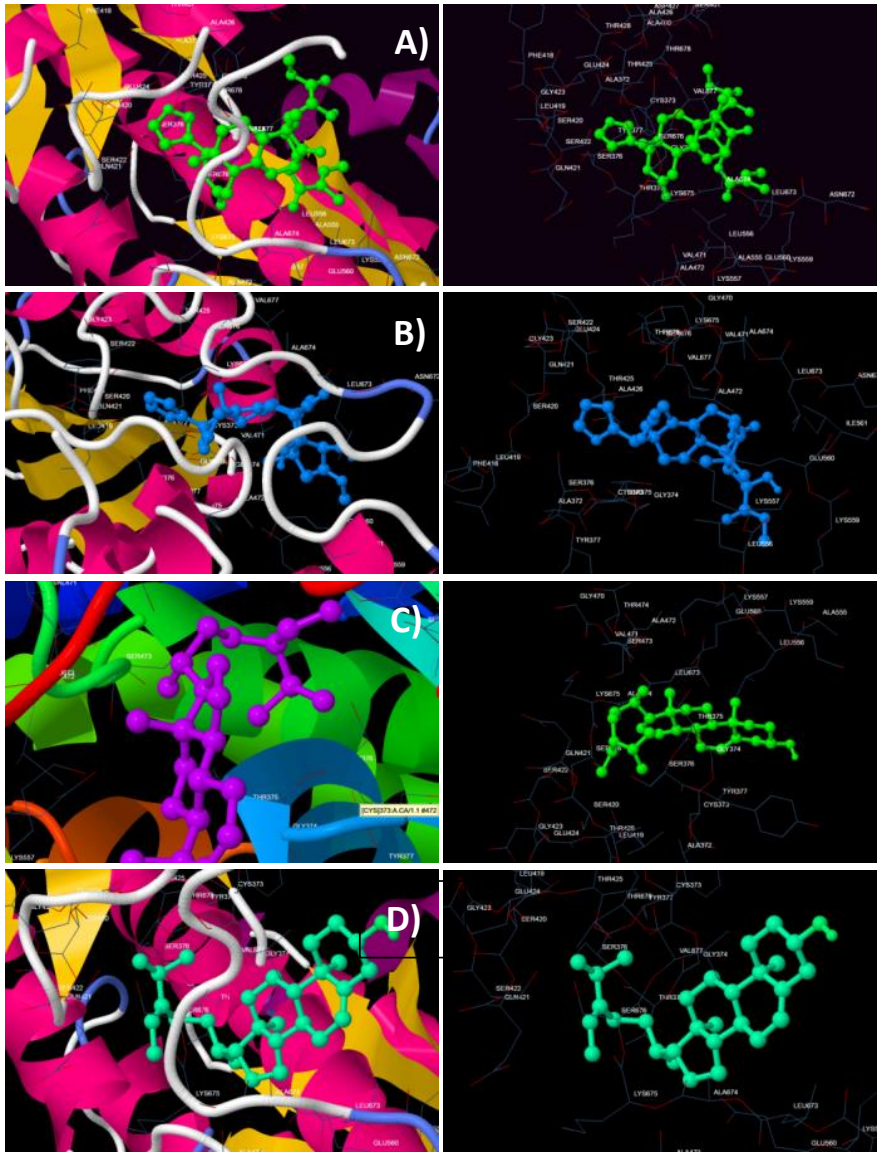

Fig. 5 Docking interactions of a) Swietenine, b) Swietenolide, c) $\beta$-Sitosterol and d) Fucosterol with active sites of 2ZJ3

Table 7 Plant compounds identified by GC-MS
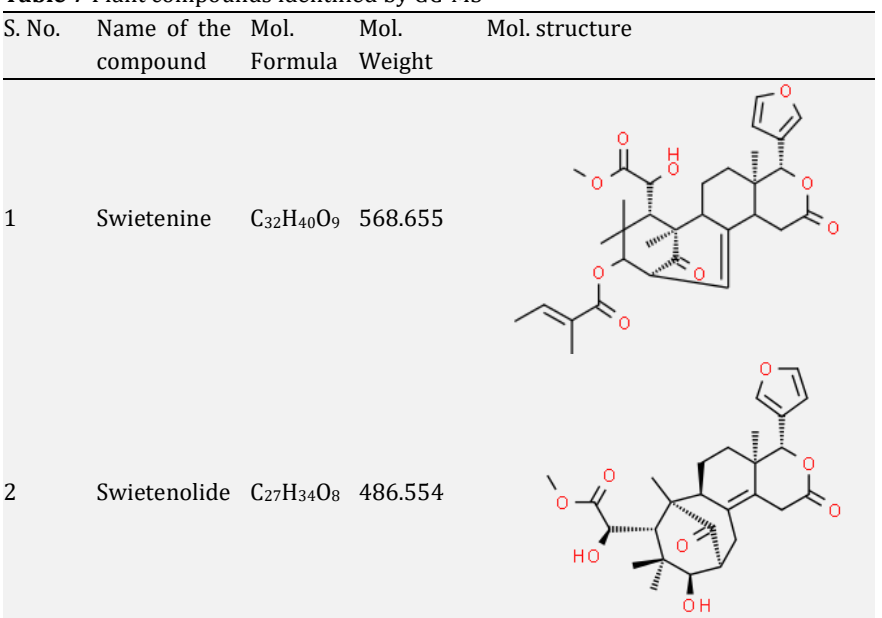

$2 \quad$ Swietenolide $\mathrm{C}_{27} \mathrm{H}_{34} \mathrm{O}_{8} \quad 486.554$

3

$\beta$-Sitosterol $\quad \mathrm{C}_{29} \mathrm{H}_{50} \mathrm{O} \quad 414.7$

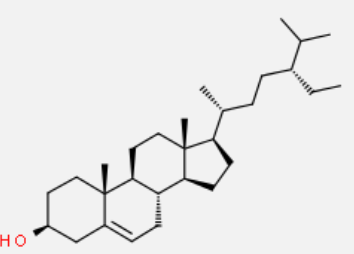

Fucosterol $\quad \mathrm{C}_{29} \mathrm{H}_{48} \mathrm{O} \quad 412.691$

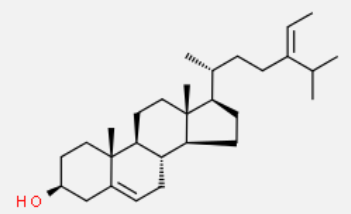

The best docked conformation was selected based on lowest docking energy and binding free energy. Docking score is a measure of interaction of the ligand to the active site of the target [38]. More negative values indicate more effective stable conformation of the bound ligand target. Our results suggests that in total 4 interactions namely swietenine with 2ZJ3 ($6.58 \mathrm{kcal} / \mathrm{mol}$ ) forms polar bonds SER 376, THR 425, THR 428, GLU 560 
and hydrophobic interactions are CYS 373, LEU 556, LEU 673, VAL 677 and other interactions are CYS 373, SER 376, SER 420, THR 425, ASP 427, THR 428, LEU 556, GLU 560, LEU 673, SER 676, VAL 677. SWietenolide with 2 ZJ3 $(-7.71 \mathrm{kcal} / \mathrm{mol})$ with residues polar bond GLU 560, SER 376, THR 425 and hydrophobic interactions are LEU 673, CYS 373, LEU 556. The other interactions are CYS 373 , SER 376, SER 420, SER 422, THR 425, LEU 556, 673, GLU 673. B-sitosterol with 2ZJ3 (-7.56 kcal/mol) residues with hydrophobic interactions LEU 556 and other interactions are THR 375, SER 376, SER 420, GLN 421, SER 422, THR 425, SER 473, LEU 556, GLU 560, LYS 675. Fucosterol with 2ZJ3 $(-7.62 \mathrm{kcal} / \mathrm{mol})$ residues with hudrophobic interactions VAL 677, LEU 673, CYS 373 then other interactions are CYS 373, THR 375, SER 376, SER 420, GLN 421, SER 422 THR 425, GLU 560, LEU 673, LYS 675, VAL 677 respectively. The 2ZJ3 is the glutamine-fructose-6-phosphate aminotransferase known as GFAT is a rate-limiting enzyme in the hexoamine biosynthetic pathway and plays an important role in type 2 diabetes. The C-terminal tail including the active site displays a rigid conformation, similar to the corresponding $E$. Coli enzyme. The diversity of the CF helix near the active site suggests the helix is a major target for drug design. Our study provides insights into the development of therapeutic drugs for type 2 diabetes.

Table 8 Interacting residues responsible for docking

\begin{tabular}{|c|c|c|c|c|c|c|c|}
\hline Docking result & $\begin{array}{l}\text { Est.free energy } \\
\text { of binding }\end{array}$ & $\begin{array}{l}\text { Est. inhibition of } \\
\text { constant, } \mathrm{Ki}, \mu \mathrm{M}\end{array}$ & $\begin{array}{l}\text { vdW + Hbond + } \\
\text { desolv energy }\end{array}$ & Electrostatic energy & Total intermole energy & Frequency & $\begin{array}{l}\text { Interact } \\
\text { surface }\end{array}$ \\
\hline Swietenine with 2ZJ3 & $-6.58 \mathrm{kcal} /$ energy & 15.04 & $-7.83 \mathrm{kcal} / \mathrm{energy}$ & $-0.06 \mathrm{kcal} / \mathrm{mol}$ & $-7.89 \mathrm{kcal} / \mathrm{mol}$ & $40 \%$ & 991.526 \\
\hline Swietenolide with $2 \mathrm{ZJ} 3$ & -7.71 kcal/energy & 2.23 & $-8.42 \mathrm{kcal} / \mathrm{energy}$ & $-0.13 \mathrm{kcal} / \mathrm{mol}$ & $-8.55 \mathrm{kcal} / \mathrm{mol}$ & $100 \%$ & 854.369 \\
\hline$\beta$ - Sitosterol with 2ZJ3 & -7.56 kcal/energy & 2.90 & -8.76 kcal/energy & $-0.02 \mathrm{kcal} / \mathrm{mol}$ & $-8.77 \mathrm{kcal} / \mathrm{mol}$ & $20 \%$ & 803.729 \\
\hline Fucosterol with $2 \mathrm{Z}] 3$ & $-7.62 \mathrm{kcal} /$ energy & 2.59 & $-8.92 \mathrm{kcal} /$ energy & $+0.01 \mathrm{kcal} / \mathrm{mol}$ & $-8.92 \mathrm{kcal} / \mathrm{mol}$ & $20 \%$ & 833.797 \\
\hline
\end{tabular}

\section{Conclusion}

Swietenia macrophylla is a wild tree species and is not known by most of the people for its edible seed. The seeds are consumed by the tribal communities of Asia for its medicinal values. Reports show that the seeds are the cheap source for the treatment of diabetic mellitus. Through our study the preliminary phytochemical, antioxidant and molecular docking studies were analysed in the edible seed of Swietenia macrophylla that exhibited its biological activity. Therefore, from the present investigation it is evident that the seed of Swietenia macrophylla contains the essential phytochemicals that act as good antioxidants. The phytochemical analysis revealed that the presence of different types of phytoconstituents.

The results obtained from the present study clearly stated that the presence of alkaloids, phenolic compounds, tannins, flavonoids, terpenoids, steroids, saponins, amino acids, proteins and carbohydrates except glycosides and cardiac glycosides in seeds of Swietenia macrophylla. In-silico molecular docking studies revealed that the swietenine, swietenolide, $\beta$ - sitosterol, and fucosterol exhibit good interactions with GFPT1 protein. GFPT1 protein plays a vital role in Type 1 and 2 diabetes mellitus, a detailed study of the physiochemical characteristics helps to understand its role in diabetes mellitus. The physiochemical parameters also supported the protein properties and then the protein undergoes with pocket finder to elucidate the sites which were ready to docking studies with ligand. In other hand the Swietenia macrophylla containing organic compounds were interact with GFPT1 protein and provide better scoring by using Autodock. This study proves that the bioactive compounds of seed extract of Swietenia macrophylla to reduce the diabetic level.

\section{References}

[1] G.R. Gandhi, P. Sasikumar, Antidiabetic effect of Merremia emarginata Burm. F in streptozotocin induced diabetic rats, Asian Pac. J. Trop. Biomed. 2(4) (2012) 281-286.

[2] W.L. Li, H.C. Zheng J. Bukuru, N. De Kimpe, Natural medicines used in the traditional Chinese medical system for therapy of diabetes mellitus, J. Ethnopharm. 92(1) (2004) 1-21.

[3] V.S. Malik, B.M. Popkin, G.A. Bray, J.P. Despres, F.B. Hu, Sugar sweetened beverages, obesity, type 2 diabetes and cardiovascular disease risk, Circulation 121(11) (2010) 1356-1364.

[4] C.J. Bailey, C. Day, Traditional treatments for diabetes, Diabetes Care 12 (5) (1989) 53-64.

[5] A.U. Rahman, K. Zaman, Medicinal plants with hypoglycaemic activity, J. Ethnopharmacol. 26 (1989) 1-55

[6] World Health Organization, Second Report of the WHO Expert Committee on Diabetes Mellitus, Technical Report Series 646, Geneva, 1980, p.66.

[7] A.M. Gray, P.R. Flatt, Pancreatic and extra-pancreatic effects of the traditional anti-diabetic plant, Medicago sativa (lucerne), Br. J. Nutr. 78 (1997) 325-334.

[8] X. Hu, J. Sato, Y. Oshida, M. Xu, O.G. Bajott, Y. Sato, Effect of Goshajinki- an (Chinese herbal medicine): Niu-che-sen-qi-wan) on insulin resistance in STZ induced diabetic rats, Diabetes Res. Clin. Pract. 59 (2003) 103-111.

[9] A. Maiti, P. Bhattacharya, S.C. Mandal, Effect of Swietenia macrophylla seeds on normal and alloxan induced diabetic rats, Orient Pharma. Exp. Med. 7 (2007) 224-227.

[10] A.J. Harborne, Phytochemical methods a guide to modern techniques of plant analysis, Springer science \& business media, UK, 1998

[11] P. Thangaraj, Pharmacological assays of plant-based natural products, Springer International Publishing, UK, 2016.

[12] P. Siddhuraju, K. Becker, Studies on antioxidant activities of Mucuna seed (Mucuna pruriensvarutilis) extract and various non-protein amino/imino acids through in vitro models, J. Sci. Food Agric. 83(14) (2003) 1517-1524.
[13] J. Zhishen, T. Mengcheng, W. Jianming, The determination of flavonoid contents in mulberry and their scavenging effects on superoxide radicals, Food Chem. 64(4) (1999) 555-559.

[14] M.S. Blois, Antioxidant determinations by the use of a stable free radical, ON Nat. 181 (1958) 1199-1200.

[15] K. Arnold, L. Boardoli, T. Schwede, The SWISS-MODEL workspace: A web-based environment for protein structure homology modeling, Bioinformatics 22 (2006) 195-201.

[16] S.C. Gill, P.H.H. Von Hippel, Calculation of protein extinction coefficients from aminoacid sequence data, Anal. Biochem. 182 (1989) 319-326.

[17] A. Bachmair, D. Finley, A. Varshavsky, In-vivo-half-life of a protein is a function of its amino terminal residue, Science 234 (1986) 179-186.

[18] D.K. Gonad, A. Bachmir, I. Wuning, J.W. Tobias, W.S. Lane, A.J. Varshavsky, University and structure of the N-end rule, J. Biol. Chem. 264 (1989) 16700 16712.

[19] J.W. Tobias, T.E. Shrader, Rocap, A. Varshavsky, The N-end rule in bacteria, Science 254 (1991) 1374-1377.

[20] A. Ciechanover, A.L. Schwartz, How are substrates recognized by the ubiquitinmediated proteolytic system, Trends Biochem. Sci. 14 (1989) 483-488.

[21] A. Ikai, Thermostability and aliphatic index of globular proteins, J. Biochem. 88 (1980) 1895-1898.

[22] J. Kyte, R.F. Doolittle, A simple method for displaying the hydropathic character of a protein, J. Mol. Biol. 157 (1982) 105-132.

[23] C. Comber, C. Blanchet, C. Geourijon, G. Deleage, NPS@Network protein sequence Analysis, Trends Biochem. Sci. 25 (2000) 147-150.

[24] T. Hirokawa, S. Boon-chieng, S. Mitaku, SOSUI classification and secondary structure prediction system for membrane proteins, Bioinformatics 14 (1998) 378-379.

[25] G.N. Ramachandran, V. Sasikharan, Conformation of polypeptides and proteins, Adv. Prot. Chem. 23 (1968) 283-437.

[26] F. Kiefer, K. Arnold, M. Kunzli, L. Bordoli, T. Schwede, The SWISS-MODEL repository and associated resources, Nucleic Acids Res. 37 (2009) D387-D392.

[27] S.C. Lovell, I.W. Davis, B. Arendall, P.I.W De Bakker, M. Word, et al., Structure validation by Có geometry: $\varphi, \psi$ and C $\beta$ deviation, Proteins: Struct. Funct. Gen. 50 (2002) 437-450.

[28] F.A. Laskowski, J.A. Fullmannn, M.W. Mac Arthur, R. Kaptein, J.M. Thornton, AQUA and PROCHECK-NMR: programs for checking the quality of protein structures solved by NMR, J. Biomol. NMR 8 (1996) 477-486.

[29] G. Vriend, WHAT IF: A molecular modelling and drug design program, J. Mol. Graph. 8 (1990) 52-56.

[30] G.M. Morris, D.S. Goodsell, R.S. Halliday, R. Huey, W.E. Hart, et al., Automated docking using a Lamarckian genetic algorithm and an empirical binding free energy function, J. Comput. Chem. 19(14) (1998) 1639-1662.

[31] S.Z. Moghadamtousi, B.H. Goh, C.K. Chan, T. Shabab, H. Abdul Kadir, Biological activities and phytochemicals of Swietenia macrophylla King, Molecules 18 (2013) 1420-3049.

[32] T.A. Halgren, Characterization of MMFF94, MMFF94s, and other widely available force fields for conformational energies and for intermolecularinteraction energies and geometries, In: Abstract of Papers of the American Chemical Society 216 (1998) U702-U702.

[33] F.J. Solis, R.J.B. Wets, Minimization by random search techniques, Math. Oper. Res. 6(1) (1981) 19-30.

[34] S. Saravanan, T. Parimelazhagan, In-vitro antioxidant, antimicrobial and antidiabetic properties of polyphenols of Passiflora ligularis Juss Fruit pulp Food Sci. Hum. Wellness 3(2) (2014) 56-64.

[35] B. Halliwell, J.M. Gutteridge, Free radicals in biology and medicine, Oxford University Press, USA, 2015.

[36] I.I. Koleva, T.A. Van Beek, J.P. Linssen, A.D. Groot, L.N. Evstatieva, Screening of plant extracts for antioxidant activity: a comparative study on three testing methods, Phytochem. Anal.: Int. J. Plant Chem. Biochem. Tech. 13(1) (2002) 817.

[37] C. Guo, J. Yang, J. Wei, Y. Li, J. Xu, Y. Jiang, Antioxidant activities of peel, pulp and seed fractions of common fruits as determined by FRAP assay, Nutr. Res. 23(12) (2003) 1719-1726.

[38] L. Inbathamizh, E. Padmini, In-silico studies on the inhibitory effects of calcitriol and 5,5'-dithiobis-2-nitrobenzoic acid on human glucosaminyl n-acetyl transferase 1 activity, Asian J. Exp. Biol. Sci. 3(1) (2021) 4-21. 